\title{
La Responsabilidad Social. Un compromiso que debe ser asumido por partida doble: Empresa y Consumidor \\ Maria Laura Estigarribia Bieber
}

Profesora Titular, por concurso, de la Cátedra de Instituciones del Derecho Privado I y Directora del Departamento de Derecho, en la Facultad de Ciencias Económicas de la Universidad Nacional del Nordeste. Miembro correspondiente de la Academia Nacional de Derecho de Córdoba. Argentina. Doctora en Ciencias Juridicas, Investigadora.

Docente, pot concurso, de las asignaturas Estados Contables y Auditoria, en la Facultad de Ciencias Económicas de la Universidad Nacional del Nordeste. Argentina. Especialista en Contabilidad Superior y Auditoria. Investigadora.
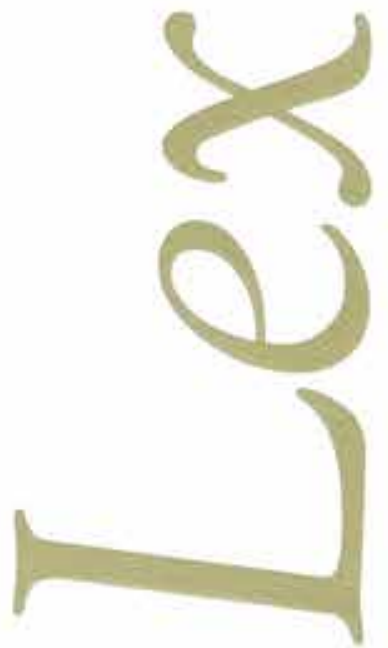


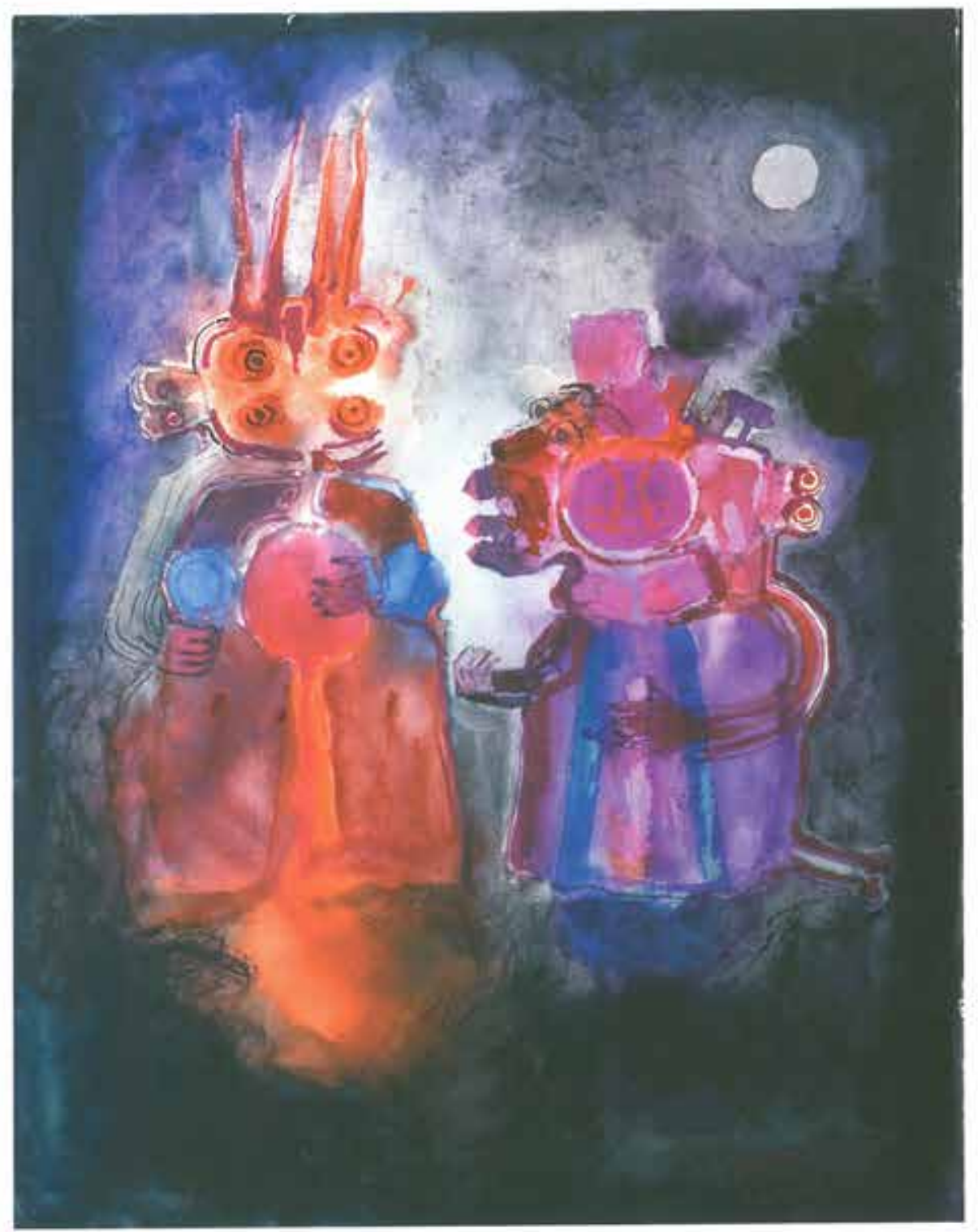

Lo vivido en Kenko. Técnica mixta, $1967(48.5 \mathrm{~cm}$. x $38 \mathrm{~cm}$.) 
"Cuando los vientos de cambio soplan, algunos construyen re. fugios y se ponen a salvo... otros construyen molinos y se hacen ricos."

Clauss Moller

\section{RESUMEN}

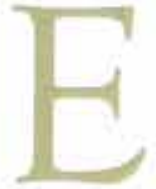

n este estudio presentamos el concepto de la Responsabilidad Social Empresaria como nuevo paradigma de conducta ética. Asimismo, hacemos hincapié en que las obligaciones que derivan de tales principios abarcan por igual a Empresarios y sus grupos de interés -entre los que hemos elegido referirnos en particular a los consumidores-, con el objetivo de conseguir la sustentabilidad del consumo y la aplicación de postulados de acción basados en un profundo sentido de justicia social, respeto por los derechos personalisimos y del medio ambiente, en pos de una mejor calidad de vida para la Comunidad toda.

Hacemos una breve referencia al estado de situación del tema en el ámbito internacional, con particular énfasis en lo que ocurre en Perú y Argentina, arribando a conclusiones que, necesariamente, tienen el carácter de provisorias; teniendo presente el proceso de dinámica actualización que experimenta el tema en estudio.

Además, ponemos de resalto que tanto organismos públicos como entes privados trabajan en la elaboración de estándares y principios referentes al sub estudio, para ser aplicados en las empresas, con intención que su cumplimento pueda resultar verificable y pasible de certificación.

De cualquier modo, a pesar de su aún escaso estado de aplicación, somos optimistas en los beneficios que puede traer consigo la implementación de la Responsabilidad Social Empresaria, asi como del Consumidor, para revertir profundas inequidades vigentes en toda nuestra América Latina, aplicando principios de solidaridad, que fortalecerản la participación de nuestros paises, en pie de igualdad, en la Gran Aldea Global.

\section{LA RESPONSABILIDAD SOCIAL}

El presente estudio aborda una problemática de suma actualidad e importancia, que tiene como protagonista a la Empresa -como emprendimiento organizativo destinado a producir 
bienes o prestar servicios, con finalidad de lucro para su titular-, con el objetivo de mostrar los diversos aspectos y sujetos que intervienen en ella, así como su proyección interdisciplinaria -teniendo presente que puede ser analizada desde las ciencias de la Administración, la Economía, la Psicología, la Sociología, la Ecología y, lógicamente, también por el Derecho.

Cabe destacar que su influencia puede ser aún metajurídica, puesto que tiene un hondo contenido ético, que trasciende el ámbito normativo. Uno de los destinatarios de estas acciones es el consumidor que, como podremos observar, está llamado a convertirse en uno de los principales actores para el logro de la imposición de la Responsabilidad Social Empresaria.

Partiremos del concepto de que "las organizaciones están cambiando. La esencia de lo que es una organización está cambiando. Con lo cual tiene que cambiar nuestra forma de pensamiento, ya que el mundo de las organizaciones traduce fielmente nuestra visión del mundo,

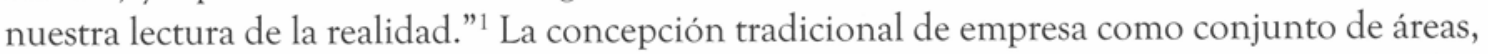
departamentos y secciones, orientada hacia su organización y problemática interna, se ha desplazado para dar lugar a la visión actual, que la considera inserta en un contexto complejo y cambiante, donde los aspectos económico, social y medioambiental se presentan íntimamente concatenados.

En este escenario, la empresa desarrolla sus actividades y toma decisiones que influyen en ella misma, en la comunidad cercana, y en la sociedad en general; con particular incidencia en sus grupos de interés, los stakeholders -clientes internos (accionistas, directivos, trabajadores) y externos (proveedores, consumidores, la comunidad y el medio ambiente)-. Esta debería agudizar su capacidad para entender el mercado actual y futuro, e internalizar que todo lo relacionado con su administración y operatoria se proyecta sobre otros factores, en una permanente interacción.

Debemos añadirle a esto, los factores tiempo y contexto, cuya inclusión en el mundo empresarial contribuyó a que se produjeran cambios muy importantes y claves en este siglo. Por esto, ya no se puede hablar de eficiencia, crecimiento y rendimiento de una empresa, sino de eficiencia global, crecimiento diferenciado y rendimiento sostenible ${ }^{2}$, donde con cada decisión que se toma, se asume un compromiso y decide el futuro de la empresa a largo plazo.

Es en este entorno, donde la Responsabilidad Social Empresaria -que siempre estuvo presente en las organizaciones, pero hoy tiene identidad propia-, conocida bajo las siglas RSE o

KASTIKA, Eduardo. Desorganización creativa Organización innovadora. Ediciones Macchi, 1996, p. 249.

Ídem, pp. 261-2. 
$\mathrm{RSC}^{3}$, se plantea como un desafío a nivel mundial, en el que las empresas asumieron o deben emprender la tarea de revertir, en algunos casos, y prevenir en otros, problemas de tipo sociales, económicos y ambientales; tornándose partícipes de sus soluciones.

La Organización Internacional de Normalización - ISO - sostiene que la Responsabilidad Social Empresaria consiste en una integración balanceada, por parte de las empresas, de las preocupaciones sociales, económicas y ambientales, con el propósito de beneficiar a las personas, las comunidades y la sociedad en general ${ }^{4}$.

Dante Pesce, fundador y director general de la organización especializada Vincular, de la Pontificia Universidad Católica de Valparaíso, define a la RSE como "un conjunto de políticas transversales y buenas prácticas verificables, tanto internas como externas, consistentes con sus valores y principios, cuya finalidad es contribuir al logro de los objetivos estratégicos de la empresa, mejorando su competitividad, sustentabilidad y la calidad de vida de sus grupos de interés" 5 .

Sostiene el mismo autor que "existe una importante masa crítica que entiende la RSE desde una perspectiva mucho más amplia, casi como un nuevo Contrato Social entre la Empresa y la sociedad en su conjunto, tanto internamente -empleados, proveedores, etc., como externamente, con el medioambiente, el gobierno, los consumidores, etc." ${ }^{6}$. Advierte, también, que dicha responsabilidad no es caridad, filantropía, maquillaje publicitario ni marketing; que se trata de inversiones que, a largo plazo, vuelven más competitiva y redituable a la compañía, incluso a las pequeñas y medianas empresas.

Por su parte, el Foro de Expertos en RSE, constituido en el seno del Ministerio de Trabajo y Asuntos Sociales de España, en 2005, nos brinda el siguiente concepto: "La responsabilidad social de las empresas es, además del cumplimento estricto de las obligaciones legales vigentes, la integración voluntaria en su gobierno y gestión, en sus estrategias, políticas y procedimientos, de las preocupaciones sociales, laborales, medioambientales y de respeto a los derechos humanos que surgen de la relación y el diálogo transparentes con sus grupos de interés, responsabilizándose así de las consecuencias y los impactos que se derivan de las acciones"?

Coincidimos con la definición brindada por el Instituto Ethos, de Brasil, al sostener que

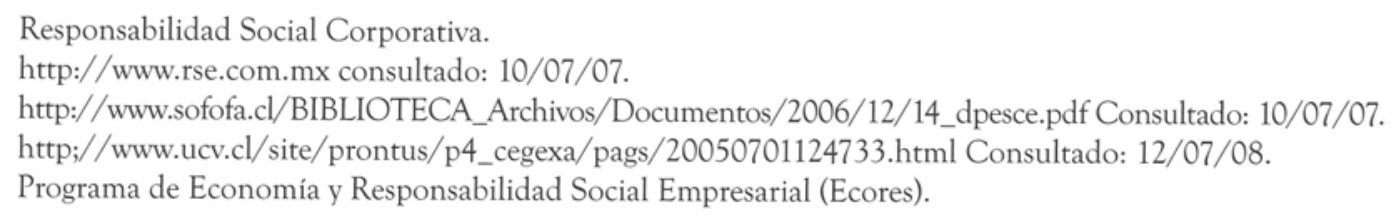


"Responsabilidad Social Empresarial es la forma de gestión definida por la relación ética y transparente de la empresa con todos los públicos con los cuales se relaciona, y por el establecimiento de metas empresariales compatibles con el desarrollo sustentable de la sociedad, preservando recursos ambientales y culturales para las futuras generaciones, respetando la diversidad y promoviendo la reducción de las desigualdades sociales"

El consultor holandés, Pierre Hupperts ${ }^{9}$, en su visita a Argentina, expresó que hay tres desafíos relacionados con la RSE: el primero es la transformación de la visión de "hacer bien en la comunidad" en otra que remarque la importancia de integrar el tema en la estrategia y la gestión de las empresas, de manera que su producto final refleje su política en tal sentido. El segundo, es vincular la RSE con los grandes problemas mundiales y el tercero es la necesidad de una mayor cooperación entre el Estado y el sector empresarial.

El concepto de Responsabilidad Social Empresaria promueve en las empresas: una nueva forma de encarar sus actividades, en la que deben encontrar el equilibrio entre los objetivos de lograr beneficios económicos y financieros, y el impacto social o ambiental de las actividades realizadas para alcanzarlos; un modelo de gestión que contempla tales impactos; el compromiso con su entorno y con la comunidad en general; y una visión a largo plazo.

Existen diversos organismos, tanto públicos como privados, de carácter nacional, regional o internacional, dedicados al análisis de esta temática y a promover las conductas socialmente responsables. Entre ellas, podemos mencionar, entre otras, a la Organización para la Cooperación y Desarrollo Económico (OCDE) que es una organización de cooperación internacional que se ha constituido como uno de los Foros Mundiales más influyente, cuyo objetivo es coordinar las políticas y sociales de sus estados miembros, promoviendo, por tanto, la RSE. Para conseguir este objetivo ha establecido líneas directrices -que establecen un conjunto de principios y estándares de aplicación voluntaria- para las empresas multinacionales, respecto al ejercicio de dicho aspecto.

Estas directrices establecen, taxativamente, a las empresas multinacionales tener en cuenta determinadas obligaciones, que resumimos en la siguiente enunciación:

8 Definición del Instituto Ethos de Brasil, citada por González Unzueta, Cristina. "Responsabilidad Social y Ética. Análisis de C\&A". Disponible en: http://www.iarse.org/site/downloads/curso_rse/Responsabilidad_Social_y_Etica-AnalisisCyA-C_ Gonzalez_U.pdf Consultado: 10/07/08.

9 http://www.rseonline.com.ar Consultado: 07/07/08. 
1. Contribuir al progreso económico, social y medioambiental con vistas a lograr un desarrollo sostenible.

2. Respetar los derechos humanos de las personas afectadas por sus actividades, de conformidad con las obligaciones y compromisos internacionales del gobierno de acogida.

3. Estimular la generación de capacidades locales mediante una cooperación estrecha con la comunidad local, incluidos los sectores empresariales locales, desarrollando al mismo tiempo las actividades de la empresa en los mercados interiores y exteriores de una manera compatible con la necesidad de prácticas comerciales saludables.

4. Fomentar la formación del capital humano, particularmente mediante la creación de oportunidades de empleo y el ofrecimiento de formación a los empleados.

5. Considerar los intereses de los consumidores, actuando conforme prácticas comerciales correctas, de manera justa, y adoptando todas las medidas razonables para garantizar la seguridad y calidad de los bienes y servicios que proporcionan.

6. Abstenerse de buscar o de aceptar exenciones no contempladas en el marco legal o reglamentario relacionadas con el medioambiente, la salud, la seguridad e higiene, el trabajo, la fiscalidad, los incentivos financieros $u$ otras cuestiones varias.

7. Apoyar y defender correctos principios de gobierno empresarial y desarrollar y aplicar buenas prácticas de gobierno empresarial.

8. Desarrollar y aplicar prácticas autodisciplinarias y sistemas de gestión eficaces que promuevan una relación de confianza recíproca entre las empresas y las sociedades en las que ejercen su actividad.

9. Promover el conocimiento por los empleados de las políticas empresariales y su conformidad con ellas, mediante una difusión adecuada de las mismas, incluso a través de programas de formación.

10. Abstenerse de tomar medidas discriminatorias o disciplinarias contra los trabajadores que elaboren, de buena fe, informes para la dirección o, en su caso, para las autoridades públicas competentes acerca de prácticas contrarias a la ley, a las directrices o a las políticas de la empresa. 
11. Alentar, cuando sea factible, a los socios empresariales, incluidos proveedores y subcontratistas, para que apliquen principios de conducta empresarial compatibles con las directrices.

12. Abstenerse de cualquier ingerencia indebida en actividades politicas locales.

En Argentina, el Instituto Argentino de Responsabilidad Social -IARSE- es el Organismo que asumió el compromiso de promover e incentivar a las empresas a desarrollar sus actividades atendiendo, también, al aspecto social y medioambiental, resaltando su importancia y beneficios. "Es una organización que trabaja para constituirse en un centro de referencia nacional en materia de Responsabilidad Social de las empresas, basándose en un conjunto de actividades y servicios orientados a todos los interesados en esta temática, pretende fortalecer el compromiso del sector de negocios de Argentina con el desarrollo sustentable de la nación..." ${ }^{10}$

El IARSE estableció los siguientes indicadores cuali-cuantitativos ${ }^{11}$ como guía y control del accionar de las empresas en ese aspecto:

a) Compromiso ciudadano en la preservación de la paz.

b) Respeto de los Derechos Humanos.

c) Equidad en el ámbito laboral.

d) Coherencia y lealtad en la relación con socios y proveedores.

e) Actitud de servicio activo a la comunidad inmediata y a la sociedad en general.

f) Comportamiento transparente en su relación con los consumidores/clientes.

g) Cuidado del medio ambiente al interior y al exterior de la empresa, aún más allá de su ámbito de influencia directa.

h) Promover la creación de empresas.

i) Responsabilidad ciudadana y total transparencia en las relaciones con la "sociedad política" (estado y partidos políticos).

Entre todos los indicadores antes enunciados, fijamos nuestra atención en el inciso f), que se refiere al comportamiento transparente en su relación con los consumidores/clientes, que resulta coincidente con el punto 5 de las Directrices de la OCDE.

Si bien Perú ni Argentina revisten la calidad de países miembros, esta última participa en carácter de observador. Por lo demás, en nuestro país, actualmente posee estado parlamentario un proyecto presentado por el legislador Carlos Alberto Raimundi, el 11 de junio de 2008, en que propone la "Creación del Punto Nacional de Contacto sobre Empresas Multinacionales, 
según compromisos gubernamentales en la Organización de Cooperación y Desarrollo Económico -OCDE- en el ámbito del Ministerio de Relaciones Exteriores, Comercio Internacional y Culto" ${ }^{12}$, en una clara muestra de la trascendencia y actualidad del tema en análisis.

Por su parte, Perú trabaja en forma intensa en el tema de la Responsabilidad Social Empresaria. Entre los Organismos actuantes, podemos mencionar al Centro de Asesoría Laboral -CEDAL- que es una Organización No Gubernamental, de derecho privado, sin fines de lucro, con amplia línea de trabajo en este campo y en la defensa de los derechos humanos en el ámbito laboral y social, cuya misión es promover los derechos de las personas como fundamento del desarrollo sustentable y la justicia económica y social en el Perú y en el ámbito regional y glo$\mathrm{bal}^{13}$. También, a la Red Puentes, que es una Alianza Internacional formada por Organizaciones sociales de América Latina y Europa, que se unieron para la promoción del desarrollo de los conceptos e instrumentos de Responsabilidad Social Empresaria en América Latina, desde la perspectiva de la sociedad civil ${ }^{14}$.

En otro orden, la Organización Internacional de Normalización -ISO- impulsó en el año 2005, la creación de un Grupo de Trabajo Internacional con delegados de los diferentes stakeholders $^{15}$ para desarrollar la Guía Internacional sobre Responsabilidad Social -Norma ISO 26000-. El conocimiento de esta guía será esencial para aquellas empresas cuya aspiración es crecer en el tiempo manteniendo calidad en sus productos y en su relación con los clientes o usuarios, proveedores, empleados y demás grupos de interés.

Según los expertos, la futura norma ISO 26000 reconocerá a la Responsabilidad Social como un elemento esencial en el buen desempeño de la empresa privada, los servicios públicos, los centros de educación y otras organizaciones sociales, pues está dirigida a guiar y garantizar la aplicación de valores, principios, procesos y prácticas de trabajo, en temas tan amplios como el respeto a los derechos humanos, el cuidado del medio ambiente y asuntos laborales, entre otros. ${ }^{16}$

Esta Norma ISO define a la RSE como la "responsabilidad de una organización respecto de los impactos de sus decisiones y actividades en la sociedad y el medio ambiente, a través de un comportamiento transparente y ético que sea:

- Consistente con el desarrollo sostenible y el bienestar general de la sociedad;

12 http://www1.hcdn.gov.ar/proyxml/expediente.asp?fundamentos=si\&numexp=3099-D-2008 Consultado: 11/07/08.

13 http://www.cedal.org.pe Consultado: 14/07/08.

14 http://www.redpuentes.org Consultado: 10/07/08.

15 Grupos de interés.

16 http://www.comunicarseweb.com.ar/biblioteca/noticias-08/0570.html Consultado: 11/07/08. 
- Considere las expectativas de sus partes interesadas (stakeholders);

- Cumpla con legislación aplicable y sea consistente con normas internacionales de comportamiento;

Y que esté integrada en toda la organización y practicada en sus relaciones." ${ }^{17}$

Las características más sobresalientes de esta Guía son: que resulta de aplicación voluntaria; no está orientada a certificación por un tercero; está dirigida tanto a empresas públicas como privadas, y a cualquier organización que pretenda dar a conocer su trabajo y comprometerse socialmente; es un documento guia con redacción sencilla y no técnica; constituye un documento único que integra todas las temáticas: principios económicos, ambientales y sociales; recomienda que las organizaciones realicen actividades más allá de sus obligaciones legales y promuevan la RSE.

En esta misma linea, "Bélgica aprobó la "ley de la etiqueta social", que garantiza a los consumidores que los productos que llevan esa etiqueta han sido elaborados con respeto por los derechos laborales, sin mano de obra infantil y sin discriminaciones" ${ }^{18}$.

La impronta que deja en las empresas una actuación socialmente comprometida, nos invita a la búsqueda de herramientas que respalden y justifiquen, la necesidad de esta actitud empresarial integrada al plan estratégico de la empresa. Para ello acudimos a una herramienta objetiva, muy utilizada en Administración, conocida como Matriz FODA (Fortalezas, Oportunidades, Debilidades y Amenazas), que podrá servir de base para el diseño de sus políticas de conducción y acción.

El análisis FODA consiste en realizar una evaluación de los factores internos fuertes y débiles, como así también, su evaluación externa a través de las oportunidades y amenazas que tiene una organización. Si aplicamos este análisis a la Responsabilidad Social Empresaria, se obtendría, a través de él, una perspectiva general que sirva de marco para su implementación. El Dr. Juan José Almagro ${ }^{19}$, al referirse al tema, enunció las siguientes fortalezas, oportunidades, debilidades y amenazas relacionadas con la RSE:

17 http://www.sofofa.com/BIBLIOTECA_Archivos/Eventos/2008/05/12_dpesce.pdf

18 Kliksberg, Bernardo. "Hacia una nueva ética empresarial". La Nación, 02/12/03. www.iarse.org Consultado: $15 / 07 / 08$.

19 Director de Comunicación y Responsabilidad Social Corporativa de un reconocido grupo económico MA. PFRE, en oportunidad de su disertación en la Facultad de Ciencias Económicas de la Universidad Nacional del Nordeste en Argentina, dictada el 4 de julio de 2008. 


\begin{tabular}{|c|c|}
\hline $\begin{array}{l}\text { Fortalezas } \\
\text { - } \text { Crea valor } \\
\text { - } \text { Robustece la cultura de la empresa } \\
\text { - } \text { Desarrolla orgullo de pertenencia } \\
\text { - Afianza el buen gobierno de la empresa } \\
\text { - } \text { Favorece y optimiza la comunicación } \\
\text { Profundiza las relaciones con todos los gru- } \\
\\
\text { pos de interés }\end{array}$ & $\begin{array}{l}\text { Debilidades } \\
\text { - La creencia de las personas/empresas que } \\
\text { con la acción social ya está cubierta la cuota } \\
\text { de Responsabilidad Social de la empresa, } \\
\text { hasta llegar, en algunos casos a confundir- } \\
\text { las. }\end{array}$ \\
\hline $\begin{array}{l}\text { Oportunidades } \\
\text { - } \quad \text { Representa una nueva forma de entender y } \\
\text { gestionar la empresa }\end{array}$ & $\begin{array}{l}\text { Amenazas } \\
\text { - } \quad \text { Que se considere una moda/tendencia } \\
\text { ting } \\
\text { - La tentación de hacerla obligatoria }\end{array}$ \\
\hline
\end{tabular}

Todo el empeño puesto en imponer los conceptos construidos para lograr una conducta socialmente responsable en los empresarios, tiene como contrapartida aquellos que se han acuñado para su aplicación al consumidor, quien también deberá ajustar su actuación a los principios del consumo sustentable.

Es así que el consumidor, además de conocer y exigir sus derechos, debe tener presente que él también tiene una responsabilidad social y considerar el impacto que su conducta tiene en las relaciones de mercado. De este modo, podrá contribuir a la generación y mantenimiento de la empresa socialmente responsable. Lo antedicho se sostiene teniendo presente que es este sujeto el destinatario final de toda la actividad del empresario y quien puede realizar la discriminación positiva, premiando con su consumo a aquellas empresas que respeten los derechos de sus clientes internos y externos, así como al medioambiente, en beneficio de todos; sus comportamientos y hábitos de compra influyen decididamente sobre el éxito o fracaso de un producto o servicio.

Podríamos definir a un consumidor responsable como a una persona informada y conciente de sus hábitos de consumo. Además de conocer y exigir sus derechos como consumidor, busca la opción de consumo con el menor impacto negativo posible sobre el medio ambiente y con un efecto positivo en la sociedad. Esta manera responsable de consumir se traduce en muchos pequeños actos y decisiones diarias, y puede llegar a atravesar, si queremos, prácticamente todos los ámbitos de nuestra vida ${ }^{20}$.

20 "El consumidor RES responsable en la sociedad". Disponible en http://www.intermonoxfam.org Consultado: 15/07/08. 
Resulta necesario fortalecer la implicación del consumidor en el proceso de compra responsable y ética. En esta formación, cumplirán un rol decisivo tanto el Estado cuanto las Asociaciones de consumidores, mediante la educación e información que deben brindar en el tema que nos ocupa.

Por lo tanto, la RSC sólo será efectiva si todos los actores sociales -empresas, administración, consumidores, sociedad civil, etc. - se involucran y juegan un papel pro activo en conseguir que la actuación de las empresas y la sociedad en general, asuman el desarrollo sostenible que equilibre el progreso económico con el progreso social y la preservación del medio ambiente ${ }^{21}$.

Resulta interesante, en este item, traer a colación lo sostenido por la Comisión Europea al respecto, al sostener que "la RSE ha evolucionado, en parte, como respuesta a las expectativas y demandas de los consumidores. En sus hábitos de consumo, éstos exigen cada vez más información y garantía de que se tienen en cuenta sus intereses, principalmente en materia social y ecológica. Por su parte, las empresas son cada vez más sensibles a estas exigencias, tanto para conservar a sus consumidores habituales, como para atraer nuevos clientes"22.

\section{LA RESPONSABILIDAD SOCIAL EMPRESARIA EN AMÉRICA LATINA}

Nos refiere Teresa Cortés que "en Latino América, existen distintos grados de avances sobre el proceso. Quisiera destacar que Brasil ya cuenta con una Norma Nacional de RS, una de las pocas normas nacionales que existe en el mundo. Me refiero la llamada ABNT 16001, publicada en diciembre de 2004 y Colombia ya posee en elaboración una Guía Nacional de RS En Chile, estamos empezando a vislumbrar las ventajas que significa la incorporación al proceso. Es necesario impulsar con mayor fuerza el debate interno respecto al tema, motivarnos y ser capaces de articular con mayor energía una alianza estratégica entre Estado, Empresa y Sociedad Civil, en la búsqueda de una mejor calidad de vida, justicia social, crecimiento y desarrollo sustentable. Las generaciones futuras agradecerán este esfuerzo común”23.

Perú participa activamente en la elaboración de la Norma ISO 26000, a través del Instituto Nacional de Defensa de la Competencia y de la Protección de la Propiedad Intelectual (INDECOPI) en su elaboración a través de un enlace de doble vía efectivizado en el Comité "espejo", es decir, de Perú a ISO e ISO a Perú, aportando la visión de las necesidades de su país y analizando los avances del contenido de la norma. Este Comité está integrado por la Confederación de trabajadores del Perú y Central de trabajadores, y la Asociación de Consumidores y Radio

\footnotetext{
Ídem.

Comisión Europea COM (2002) 347 final, p. 24.

CORTÉs, María Teresa. "Responsabilidad Social: Un desafio latente". Disponible en http://www.institutojorgeahumada.cl Consultado: 14/07/08.
} 
programas del Perú, en representación de los trabajadores y de los consumidores, respectivamente. También las ONG y Universidades representativas del sector académico. Asimismo, la Escuela de Postgrado de la Universidad Peruana de Ciencias Aplicadas es la encargada de brindar apoyo logístico.

En Argentina, el Instituto Argentino de Normalización y Certificación -IRAM-, como representante de Argentina ante ISO, tiene a su cargo la coordinación de un Comité de Responsabilidad Social encargado de acompañar el desarrollo de la norma, en el que están representados todos los grupos de interés (gobierno, consumidores, empresarios, entre otros).

Asimismo, la Ley de Reforma Laboral, № $25.877^{24}$, impone a las empresas que posean más de trescientos empleados la elaboración anual de un balance social ${ }^{25}$, cuyo contenido debe incluir información sistematizada relativa a las condiciones de trabajo y empleo, costo laboral y prestaciones sociales a cargo de la empresa, que deben ser presentados a los sindicatos respectivos, con personería gremial, enviando una copia al Ministerio de Trabajo, Empleo y Seguridad Social de la Nación, siendo esta información estrictamente confidencial ${ }^{26}$. Obviamente, la difusión de esos resultados puede redundar en beneficio del prestigio de la empresa y la confianza que genera. Podemos considerar esta medida como un avance en la verificación de cumplimiento de algunos aspectos de tales principios; sin embargo, tal vez resultaría interesante poder estandarizar su contenido, ampliar los temas a informar y establecer la posibilidad de ser auditados como indicador de RSE

La complejidad del mundo actual exige distinguir ante entre la excesiva información que disponible, lo trascendente de lo no relevante, para actuar sobre lo primero y poder, de ese modo, proyectarse en el tiempo. Es aquí donde aparece la figura del cliente, usuario o consumidor ubicada en un lugar preferencial. "El servicio al cliente es brindar lealtad y compromiso, porque los clientes leales terminan siendo siempre los más leales. Y la lealtad es mucho más que la satisfacción puntual" 27 . Para el logro de esta fidelidad, la empresa debe atender aspectos importantes de su relación, tales como, la calidad del producto, los servicios de garantías, información confiable, cumplimiento de la legislación vigente, entre otros.

5 . Elarticulo 26 de mayor importancia para nuestro análisis: ...c) incidencia del costo laboral; ...f) rotación del personal por edad sexo; g) capacitación; h) personal efectivizado; ...j) estadisticas sobre accidentes de trabajo y enfermedades inculpables; ...l) programas de innovación tecnológica y organizacional que impacten sobre la plantilla de personal o puedan involucrar modificación de condiciones de trabajo.

26 Artículo 25 de la Ley 25.877.

27 BiLancio, Guillermo. Marketing el valor de provocar, Buenos Aires: Pearson Education S.A., 2005, p. 129. 
El último aspecto enunciado encuentra su parámetro en la normativa sobre la defensa del Consumidor, donde se establecen preceptos que deben ser respetados por ambas partes, con un sesgo protectorio hacia el Consumidor, en virtud de su debilidad estructural en el mercado.

La existencia de estas normas pone en evidencia la importancia que tiene el comportamiento del proveedor de bienes y servicios respecto al consumidor o usuario, enmarcada en la Responsabilidad Social que asume en su actividad, cuya trascendencia social se ve reflejada en la gran cantidad de personas afectadas y, a la vez, resulta útil para la generación de confianza -factor imprescindible para el desarrollo de las relaciones de consumo-.

Por otro lado, no podemos dejar de mencionar a la Norma sobre Responsabilidad Social -SA 8000 - elaborada por la Organización sin fines de lucro, denominada Responsabilidad Social Internacional (SAI) ${ }^{28}$, dedicada al desarrollo, implementación y control de normas de responsabilidad Social verificables y voluntarias ${ }^{29}$. Está destinada a constatar y certificar el cumplimiento de la Responsabilidad corporativa. Se aplica a todo tipo de empresas, con independencia de su envergadura.

La SA 8000 establece pautas verificables para certificar el desempeño de las empresas en nueve áreas esenciales con el objeto de mostrar a sus clientes y otros usuarios la importancia que le brindan al bienestar de sus empleados, traducida en evitar el trabajo infantil, el trabajo forzado, la discriminación; respetar la libertad de asociación, las normas de higiene y seguridad, los horarios de trabajo y el nivel de las remuneraciones; establecer prácticas disciplinarias respetuosas de la dignidad del trabajador; realizar una gestión acorde a la ética.

Para ello, esta norma internacional define cada una de estas áreas y especifica las prohibiciones y buenas prácticas relacionadas con cada una de ellas.

También resulta dable destacar que la adhesión a Métodos Alternativos de Resolución de Conflictos, entre los cuales podemos mencionar al Sistema Arbitral de consumo, también constituye una clara muestra de Responsabilidad Social Empresaria ${ }^{30}$, al permitir una solución pronta, eficaz y económica a las disputas que podrían presentarse en las relaciones de consumo.

\footnotetext{
Social Accountability Internacional

http://www.dnv.com.ar/certificacion/responsabilidadsocialcorporativa/socialaccountability/SA8000.asp

Rodriguez, Maria. "La opinión y valoración de los consumidores sobre la Responsabilidad social de la Empresa en España. Edición 2a”. Disponible en http://www.cecu.es/RSE2.pdf Consultado: 14/07/08.
} 
Asimismo, y respecto a otro de los protagonistas de esta nueva forma de gestión, debemos recordar lo sostenido por Juan Trímboli -Consumers Internacional, Oficina para América Latina y el Caribe- , al sostener que "los consumidores no sólo tenemos derechos, también tenemos responsabilidades. La responsabilidad social empresarial debe ser correspondida por la responsabilidad social del consumidor. Y para ejercerla es fundamental la transparencia de la información en paises que, a la vez, estén integrados socialmente. Solo así, la inmensa mayoria de los consumidores y no solamente algunos, tendrá posibilidades reales de seleccionar aquellos productos y servicios que más contribuyan a fortalecer una producción y un consumo sustentable. Sólo así, el consumidor adoptando una postura ciudadana marcada por su preocupación por el conjunto de la sociedad y el medio ambiente, estará agregando valor al mundo de la empresa" ${ }^{31}$.

\section{CONCLUSIONES}

La exposición que antecede pretende presentar un panorama sobre la Responsabilidad Social Empresaria y sus connotaciones en la relación entre proveedores y consumidores; poniendo de resalto muy especialmente la importancia de la participación de cada uno de estos sujetos para su construcción.

Para ello, los operadores juridicos tenemos por delante la tarea de implementar normas y procedimientos que permitan exigir aquellas conductas derivadas de la aplicación del principio de buena fe objetiva; los expertos en ciencias contables, podrán trabajar en el establecimiento de parámetros que permitan medir y auditar debidamente su cumplimiento; el Estado deberá cumplir con su obligación de difusión de la RSE entre los proveedores y en la educación al consumidor y el fomento a la constitución de asociaciones que los agrupen; y estos últimos, su comportamiento comprometido con tales postulados.

El protagonismo inminente del sector empresarial en el desarrollo sustentable de nuestra sociedad se ve potenciado, bajo este concepto, en la articulación de la trilogía que conforma junto al Gobierno y la Sociedad Civil, provocando una alianza estratégica que contribuye, sin duda, al desarrollo de la justicia social ${ }^{32}$.

Recordemos que, en toda su dimensión, la RSE supera el ámbito de normas legales, éticas y comerciales conocidas, expandiéndose en una modalidad de conducta en pro de un consumo sustentable. "En este proceso se hace necesario, por lo tanto, asumir la necesidad de avanzar

3t Trimbol, Juan. "Consumidores, empresarios y responsabilidad social". Santiago de Chile. Disponible en http://www.accionrse.cl.congreso/home/presentaciones/JuanTrimboli.doc Consultado: 15/07/08.

32 Cortés, Maria Teresa. Op. Cit. 
en tres direcciones: el desarrollo y fortalecimiento de las organizaciones de consumidores, el cumplimiento por parte del Estado de sus obligaciones reguladoras y educativas en el ámbito de las relaciones de consumo, e impulsar diversas iniciativas de RSE"33.

Evidentemente, cuando la ética, el respeto por los derechos personalísimos de nuestros semejantes y por nuestro planeta -en vista al bienestar de ésta y venideras generaciones- se encuentren impuestos en los actores de la relación de consumo, el escenario habrá evolucionado hacia la sustentabilidad; mediante la implementación de criterios de evitación y prevención de daños, basados en la solidaridad. Ello brindará la posibilidad concreta de aumentar la competitividad de América Latina y contribuir a su inserción en el mundo desarrollado, dejando de lado la mácula que significa la exclusión social y económica que hoy, lamentablemente, padecemos; trocándola en equidad y justicia social.

\section{BIBLIOGRAFÍA}

BILANCIO, Guillermo. Marketing el valor de provocar. Buenos Aires: Pearson Education S.A., 2006.

CORTÉS, María Teresa. "Responsabilidad Social: Un desafío latente”. Disponible en http:// www.institutojorgeahumada.cl Consultado: 14/07/08.

"El consumidor RES responsable en la sociedad". Disponible en http://www.intermonoxfam. org Consultado: 15/07/08.

GONZÁLEZ UNZUETA, Cristina. "Responsabilidad Social y Ética. Análisis de C\&A". Disponible en: http://www.iarse.org/site/downloads/curso_rse/Responsabilidad_Social_y_EticaAnalisisCyA-C_Gonzalez_U.pdf Consultado: 10/07/08.

GUILLÉN PARRA, Manuel. Ética en las organizaciones. Construyendo confianza. Madrid: Editorial Pearson Educación S.A., 2006.

KASTIKA, Eduardo. Desorganización creativa. Organización innovadora. Buenos Aires: Ediciones Macchi, 1996.

KLIKSBERG, Bernardo. "Hacia una nueva ética empresarial”. La Nación, 02/12/03. www. iarse.org Consultado: 15/07/08.

33 Trímboli, Juan. Derechos de los Consumidores y Responsabilidad Social de la Empresa. Disponible en http:// www.ceda.org.ec Consultado: 12/07/08. 
"Programa de Economía y Responsabilidad Social Empresarial (Ecores)". Disponible en http:// ecodes.org/pages/areas/rsc/index.asp Consultado: 15/07/08.

“QQué es un consumidor responsable?”, Disponible en http://redpuentes.org/noticias/noticias.rse/queessonsumoresponsable. Consultado: 13/07/08.

"Responsabilidad Social Empresaria”, Pontificia Universidad Católica de Valparaíso http:// www.vincular.org/html/index.html Consultado: 10/07/08.

RODRÍGUEZ, María. "La opinión y valoración de los consumidores sobre la Responsabilidad social de la Empresa en España. Edición 2a”. Disponible en http://www.cecu.es/RSE2.pdf Consultado: 14/07/08.

TRÍMBOLI, Juan, "Derechos de los Consumidores y Responsabilidad Social de la Empresa”, Disponible en http://www.ceda.org.ec Consultado: 12/07/08.

TRÍMBOLI, Juan. "Consumidores, empresarios y responsabilidad social". Santiago de Chile, 2004. Disponible en http://www.accionrse.cl.congreso/home/presentaciones/JuanTrimboli. doc Consultado: 15/07/08.

\section{SITIOS WEB REFERENCIADOS}

http://www.cedal.org.pe

http://www.dnv.com.ar

http://www.redpuentes.org

http://www.sofofa.cl/BIBLIOTECA

http://www.ucv.cl

http://www.rse.com.mx

http://www.rseonline.com.ar

http://www.iarse.org.ar

http://www1.hedn.gov.ar

http://www.dnv.com.ar/certificacion/responsabilidadsocialcorporativa

http://www.comunicarseweb.com.ar/biblioteca 